\title{
A Sexualidade da Mulher na Relação Conjugal Violenta
}

\author{
The Women's Sexuality in the Violent Marital Relationship
}

La Sexualidad de la Mujer en la Relación Conyugal Violenta

\author{
Daliane Fontenele de Souza \\ Universidade Federal do Piauí, Brasil \\ daliane.souza@hotmail.com \\ Inez Sampaio Nery \\ Universidade Federal do Piauí, Brasil \\ inezsampaionery11@gmail.com
}

\section{Resumo}

O estudo objetivou descrever e discutir a vivência da sexualidade das mulheres vítimas, atendidas no Juizado de Violência Doméstica e Familiar Contra a Mulher, da Comarca de Teresina, PI. Tratase de uma pesquisa descritiva, com abordagem qualitativa, que utilizou o método Narrativas de Vida e a análise dos dados do tipo temática. Contou com a participação de cinco mulheres. $\mathrm{O}$ instrumento utilizado para a produção dos dados foi um formulário de pesquisa com uma questão norteadora referente à sexualidade. A técnica empregada foi a entrevista em profundidade. A partir dos relatos, constatou-se a dificuldade das mulheres em falar sobre sua sexualidade, principalmente pelas lembranças, na maioria das vezes, negativas desses momentos vividos. Ao abordarem o assunto, referiram-se mais às relações sexuais em si, ressaltando o estupro conjugal, o sexo sem vontade apenas para satisfazer o companheiro e as relações sexuais extraconjugais.

Palavras-Chave: Gênero; Violência Doméstica e Familiar; Sexualidade.

\begin{abstract}
The study aims to describe and discuss the experience of sexuality of women victims attending the Juvenile Court of Domestic and Family Violence against Women of the District of Teresina, PI. This is a descriptive research with a qualitative approach, which used the Narratives of Life method and the data analysis being the thematic type. With the participation of five women. The instrument used for the data production was a survey form containing a guiding question of sexuality. The technique used was the in-depth interview. From the reports, it was noticed the difficulty of women to talk about their sexuality, especially the memories most of the times negative of those moments. When addressing the subject, reported rather to sex itself, emphasizing marital rape, unwilling sex just to satisfy the partner and extramarital sex.
\end{abstract}

Keywords: Gender; Domestic and Family Violence; Sexuality.

\section{Resumen}

Este estudio tuvo como objetivo describir y discutir la vivencia de la sexualidad de las mujeres víctimas atendidas en el Juzgado de Violencia Doméstica y Familiar Contra la Mujer de la comarca de Teresina-PI. Se trata de una investigación descriptiva, con un enfoque cualitativo, que utiliza el 
método de narrativas de vida y análisis de datos temático. Contó con la participación de cinco mujeres. El instrumento utilizado para la producción de datos fue un formulario de investigación con una pregunta guía relacionada con la sexualidad. La técnica empleada fue la entrevista en profundidad. A partir de los relatos, se constató la dificultad de las mujeres de hablar sobre su sexualidad, especialmente por los recuerdos mayoritariamente negativos de los momentos vividos. Al abordar la cuestión, se referían a las relaciones sexuales en si mismas, resaltando la violación conyugal, el sexo sin ganas solo para satisfacer el compañero y a las relaciones sexuales extraconyugales.

Palabras-Clave: Género; Violencia Doméstica y Familiar; Sexualidad.

\section{Introdução}

A sexualidade é uma necessidade básica do ser humano, não é sinônimo de atividade sexual e não tem o mesmo grau de importância para todos os sujeitos. Ela é uma construção sócio-histórica e cultural, influenciada pelas relações de poder.

No que diz respeito à sexualidade brasileira, são importantes os dados colhidos pela Pesquisa de Opinião Pública 'A mulher brasileira nos espaços público e privado', realizada pela Fundação Perseu Abramo, em 2001: 79\% do total das mulheres pesquisadas declararam-se 'satisfeitas' com a sua sexualidade e $61 \%$ afirmaram estar 'totalmente satisfeitas' com a sexualidade. A pesquisa retratou, ainda, que: $70 \%$ estavam vivendo uma relação de intimidade com um parceiro; $51 \%$ declararam ter sentido muito prazer na maior parte de suas relações sexuais; $27 \%$ afirmaram ter achado 'gostoso'; a média de parceiros sexuais declarada foi 2,5 por mulher; $70 \%$ declararam ter certeza ou suspeitarem de já terem sido traídas; e somente $7 \%$ declararam ter tido outro parceiro sexual dentro de uma relação estável (CHACHAM; MAIA, 2004).

Sobre essa pesquisa, Chacham e Maia (2004) colocam algumas questões problemáticas: como medir a satisfação sexual dessas mulheres? A que as entrevistadas estavam se referindo quando afirmaram tanta satisfação com sua vida sexual? À capacidade de ter orgasmos, à qualidade da intimidade e da relação afetiva, à frequência de relações sexuais ou a outros indicadores que talvez nem se tenha imaginado? Para as autoras, a homogeneidade de respostas, em relação a um aspecto da vida tão complexo, é surpreendente e parece que o discurso de uma felicidade geral na cama reafirma o autoconceito que os brasileiros têm de povo sensual e sexual.

Ao considerar o impacto que a violência doméstica e familiar tem sobre a sexualidade das mulheres vítimas dessa violência, julgouse oportuno desenvolver um estudo com as vítimas atendidas no Juizado de Violência Doméstica e Familiar contra a Mulher, da Comarca de Teresina, PI. O objeto desta pesquisa foi a vivência da sexualidade das mulheres vítimas de violência doméstica e familiar.

Este artigo está estruturado em quatro partes. Na primeira parte descreve-se a abordagem metodológica quanto ao tipo, cenário e participantes da pesquisa, o método Narrativas de Vida, a produção e análise dos dados e os aspectos éticos. Na segunda parte discute-se gênero e sexualidade. Na terceira parte abordam-se as narrativas de vida de mulheres em relações conjugais violentas sobre a vivência da sexualidade com o(s) parceiro(s). Na quarta parte apresentam-se as considerações finais do trabalho que mostram algumas conclusões tiradas a partir dos resultados obtidos por meio da pesquisa e das 
entrevistas efetuadas

\section{Metodologia}

A pesquisa foi do tipo descritiva, com abordagem qualitativa. O método utilizado foi o que hoje se chama Narrativas de Vida, anteriormente conhecido como 'História de Vida'. A opção por esse método deu-se, principalmente, porque as respostas quantitativas têm sido consideradas insuficientes na busca de explicações sobre a sexualidade das mulheres vítimas de violência doméstica e familiar. Também deveu-se à natureza da temática a ser pesquisada, ao ser humano e sua realidade, com toda a riqueza de significados dessa própria realidade; e à intenção de aprofundar o conhecimento (sem generalizá-lo) e a compreensão do ser humano, em especial das mulheres vítimas de violência doméstica e familiar, principalmente no que diz respeito à vivência de sua sexualidade.

O cenário escolhido para a realização da pesquisa foi o Juizado de Violência Doméstica e Familiar contra a Mulher, da Comarca de Teresina, PI. A escolha se deu pela importância que o mesmo exerce dentro da Rede de Enfrentamento à Violência contra as Mulheres, juntamente com outras instituições. As participantes do estudo foram cinco mulheres vítimas de violência doméstica e familiar, atendidas no referido Juizado, que conviveram e/ou estavam convivendo com seu cônjuge/companheiro agressor.

A produção de dados desta pesquisa utilizou, para abordar as participantes, a técnica de entrevista do tipo aberta ou prolongada. As entrevistas ocorreram entre os meses de junho e setembro de 2014 e foram realizadas no Juizado de Violência Doméstica e Familiar contra a Mulher, da Comarca de Teresina, PI. As entrevistas foram registradas em gravador de voz digital, com autorização prévia das participantes, e transcritas manualmente pela própria pesquisadora. Para Santos e Santos (2008), a transcrição feita pela própria entrevistadora permite-lhe que se autoavalie, o que possibilita ajustes na trajetória do estudo e um crescimento pessoal.

As entrevistas tiveram como questão norteadora: 'Fale sobre sua vida relacionando os fatos importantes que tenham relação com a sua sexualidade antes e durante o relacionamento com seu atual parceiro'. Ressalta-se que, seguindo indicações de Bertaux (2010), o modelo de análise proposto não extraiu do relato de vida todos os significados que continha, mas somente aqueles pertinentes que podiam ajudar na construção do objeto de investigação. Para tratamento dos dados, foi utilizada a análise temática que consiste em descobrir os núcleos de sentido que compõem a comunicação, cuja frequência de aparição pode significar alguma coisa para o objetivo analítico escolhido.

Antes de ir ao campo, o projeto de pesquisa foi cadastrado na Plataforma Brasil, encaminhado ao Comitê de Ética em Pesquisa (CEP) da Universidade Federal do Piauí (UFPI) e aprovado sob o CAAE $\mathrm{n}^{\circ}$ 33975114.7.0000.5214, e autorizado pela instituição onde foi realizada a pesquisa. Às participantes do estudo foi apresentado o Termo de Consentimento Livre e Esclarecido, garantindo confidencialidade, privacidade, proteção da imagem, a não estigmatização e a não utilização de informações que venham conferir prejuízos às pessoas envolvidas, conforme os dispositivos da Resolução $\mathrm{n}^{\circ} 466 / 12$ do Conselho Nacional de Saúde (BRASIL, 2012). O anonimato teve a sua garantia assegurada com a substituição dos nomes das depoentes pela sigla ENT e numeração sucessiva, conforme a sequência em que as entrevistas aconteceram. 


\section{Sexualidade}

A Organização Mundial de Saúde (1975) entende a sexualidade humana como parte integrante da personalidade de cada um. Consiste em uma necessidade básica do ser humano que não pode ser separada de outros aspectos da vida (biopsicossocial e cultural). Sexualidade é mais que coito e orgasmo, é energia que motiva a encontrar o amor, a intimidade, expressando-se na forma de sentir, de como as pessoas tocam e são tocadas.

Segundo Freud (1977) apud Fernandes e Nascimento (2011), a sexualidade inclui as ações preliminares ao ato sexual, as perversões e as experiências sexuais do indivíduo, vividas desde a infância.

Garcia-Roza (2001) afirma que a sexualidade faz sua entrada nos escritos de Freud em sua obra 'Estudos sobre a histeria' e, posteriormente, na obra 'Três ensaios sobre a sexualidade', que trata não do instinto sexual, mas da pulsão sexual. Ressalta que o tema desses ensaios é o pequeno 'perverso polimorfo' com sua sexualidade fragmentada em pulsões parciais vagando entre objetos e objetivos perversos:

[...] o objeto sexual é a pessoa de quem procede a atração sexual e o objetivo sexual é o ato a que a pulsão conduz. Essa distinção pode, sem dúvida, aplicar-se também ao instinto. A diferença está em que nele temos padrões fixos de conduta ligando o objetivo ao objeto, enquanto na pulsão esses padrões são fixados durante a história do indivíduo. $\mathrm{O}$ critério do que seja um desvio é, pois, muito mais variável no caso da pulsão do que no caso do instinto (GARCIA-ROZA, 2001, p. 96-97).
Taquette (2008), embasada na teoria freudiana, enfatiza que a sexualidade é uma característica própria do ser humano, está presente desde o início de sua formação e que a libido é caracterizada por manifestações involuntárias. Ressalta que, em imagens ultrassonográficas do bebê ainda no útero, pode-se verificar a ereção peniana do sexo masculino e a lubrificação vaginal do sexo feminino.

Ressalta, ainda, que as sensações sexuais acompanham o ser humano durante todo o seu desenvolvimento: na criança, com a própria amamentação; e, na adolescência, com a intensificação, na fase da puberdade, das manifestações proporcionadas pelo desenvolvimento físico e psicológico. Enfatiza que o interesse sexual aumenta proporcionalmente ao desenvolvimento físico, o qual é observado pelo surgimento das características sexuais secundárias (distribuição de pelos no corpo, tonalidade da voz, distribuição de gordura no corpo, massa muscular), com consequentes alterações hormonais que favorecem o prazer sexual sem a finalidade reprodutiva (TAQUETTE, 2008).

Para Chauí (1984), o fenômeno da sexualidade é tão antigo quanto a vida humana em sociedade. Argumenta que as práticas sociais de controle, de proibição e permissão da sexualidade são antigas, porém, o estudo de seu sentido, de suas causas, de suas variações no tempo e no espaço é recente.

$\mathrm{O}$ enfoque sobre sexualidade assumido neste trabalho é o de Foucault (1988). O autor aponta que o termo sexualidade surgiu tardiamente, apenas no início do século XIX, e que nasceu como a justa medida de separação entre normalidade e anormalidade. $\mathrm{Na}$ obra que produziu em três volumes, 'História da Sexualidade', Foucault tomou a sexualidade como uma criação discursivoinstitucional, cuja função seria o controle dos 
indivíduos e das populações.

Considerava que, nas relações de poder, a sexualidade não é o elemento mais rígido, mas um dos dotados da maior instrumentalidade: "utilizável no maior número de manobras, e podendo servir de ponto de apoio, de articulação às mais variadas estratégias" (FOUCAULT, 1988, p. 114). O autor afirmava que:

[...] a sexualidade é o nome que se pode dar a um dispositivo histórico: não à realidade subterrânea que se apreende com dificuldade, mas à grande rede da superfície em que a estimulação dos corpos, a intensificação dos prazeres, a incitação ao discurso, a formação dos conhecimentos, o reforço dos controles e das resistências, encadeiam-se uns aos outros, segundo algumas grandes estratégias de saber e de poder (FOUCAULT, 1988, p. 116-117).

Para ele, a partir do século XVIII, parece possível distinguir quatro grandes conjuntos estratégicos que desenvolvem dispositivos específicos de saber e poder a respeito do sexo: histerização do corpo da mulher; pedagogização do sexo da criança; socialização das condutas de procriação; e psiquiatrização do prazer perverso (FOUCAULT, 1988).

Foucault ressalta que a personagem investida, em primeiro lugar, pelo dispositivo de sexualidade, uma das primeiras a ser "sexualizada", foi a mulher "ociosa", "nos limites do 'mundo' - onde sempre deveria figurar como valor - e da família, onde lhe atribuíram novo rol de obrigações conjugais e parentais: assim apareceu a mulher 'nervosa', sofrendo de "vapores"” (FOUCAULT, 1988, p. 132). Enfatiza que foi aí que a histerização da mulher encontrou seu ponto de fixação.

Segundo o mesmo autor, estamos em uma sociedade do 'sexo', ou melhor, 'de sexualidade':

[...] os mecanismos do poder se dirigem ao corpo, à vida, ao que a faz proliferar, ao que reforça a espécie, seu vigor, sua capacidade de dominar, ou sua aptidão para ser utilizada. Saúde, progenitura, raça, futuro das espécies, vitalidade do corpo social, o poder fala da sexualidade e para a sexualidade; quanto a esta, não é marca ou símbolo, é objeto e alvo. O que determina sua importância não é tanto sua raridade ou precariedade quanto sua insistência, sua presença insidiosa, o fato de ser, em toda parte, provocada e temida. O poder a esboça, suscita-a e dela se serve como um sentido proliferante de que sempre é preciso retomar o controle para que não escape; ela é um efeito com valor de sentido (FOUCAULT, 1988, p. 160-161).

Acredita-se na sexualidade como instrumento de poder e que os demais instrumentos de poder exercem influência sobre a sexualidade, principalmente na sexualidade das mulheres. Historicamente, as mulheres tiveram suas vidas regidas por ditames morais que, ao mesmo tempo que reprimiam ou expunham o seu 'sexo', também invisibilizavam e homogeneizavam os seus desejos e necessidades enquanto sujeitos. No entanto, sabe-se que a sexualidade não tem o mesmo grau de importância para todos os sujeitos.

Heilborn (1999) afirma que o valor diferencial atribuído à sexualidade deve considerar que esta não é sinônimo de atividade sexual. Mais do que um recurso 
explicativo baseado em diferenças psicológicas, essa variação é:

[...] efeito de processos sociais que se originam no valor que a sexualidade ocupa em determinados nichos sociais e nos roteiros específicos de socialização com que as pessoas se deparam. A cultura, em sentido lato, é a responsável pela transformação dos corpos em entidades sexuadas e socializadas, por intermédio de redes de significados que abarcam categorizações de gênero, de orientação sexual, de escolha de parceiros. Valores e práticas sociais modelam, orientam e esculpem desejos e modos de viver a sexualidade, dando origem a carreiras sexuais/amorosas (HEILBORN, 1999, p. 1).

Grossi (1998, p. 9) ressalta que, na cultura ocidental, costuma-se associar a sexualidade ao gênero, como se fossem duas coisas coladas uma à outra. Por isso, classificam-se indivíduos que mantêm relações sexuais e/ou afetivas com outros do mesmo sexo como homossexuais, "uma categoria que remete imediatamente, no imaginário ocidental, à ideia de doença, perversão ou anormalidade".

De acordo com a autora, a sexualidade é também culturalmente determinada. Alega que a maior parte das pessoas, na sociedade ocidental, considera a heterossexualidade algo 'instintivo' da espécie humana em vistas da sua autoperpetuação pela reprodução. Alega ainda que sexo e reprodução são vistos nesta sociedade como intrinsecamente relacionados entre si, pois se considera a reprodução como envolvendo apenas os dois indivíduos, de sexos diferentes, que se relacionaram sexualmente. Para ela, o desenvolvimento, no final do século XX, das ditas 'novas tecnologias de reprodução' tem vindo abalar esta crença, desvinculando, portanto, a sexualidade da reprodução (GROSSI, 1998).

Da mesma forma que hoje se discute se a heterossexualidade é necessária à reprodução da espécie humana, no final do século XIX, pensava-se que:

[...] o desejo sexual era uma característica masculina e que as mulheres copulavam apenas para as necessidades de reprodução da espécie e da família. O prazer feminino era percebido como perigoso e patológico, sendo que passividade e frigidez eram consideradas comportamentos femininos "naturais", portanto ideais. Hoje, com as inúmeras contribuições da Psicanálise e dos movimentos de libertação das mulheres, o desejo e o orgasmo femininos não são mais vistos como pecaminosos ou "antinaturais". Vemos, portanto, que os valores associados às práticas sexuais são marcados historicamente (GROSSI, 1998, p. 10).

Lima (2012, p. 85), ao trabalhar a dimensão simbólica de gênero de Scott (1990), argumenta que os padrões 'Maria, a virgem' e 'Maria, a pecadora' são estereótipos que tendem a padronizar a sexualidade da mulher, pois esta foi condicionada a exercer sua sexualidade não em prol do prazer, mas em busca da procriação. A autora reporta que "prazer e gozo femininos foram, por vários anos, considerados sensações proibidas às 'mulheres direitas', sendo sentimentos associados às mulheres consideradas 'devassas ou prostitutas"'.

A despeito de tantas nulidades no exercício do direito de viverem sua 
sexualidade como algo que lhes desse prazer e não só como atividade reprodutiva, as mulheres tiveram, ao longo do tempo, vários eventos que colocaram em pauta sua situação de subordinação na sociedade capitalista.

A IV Conferência Mundial da Mulher em Pequim, em 1995, avançou alguns passos no sentido de afirmar o direito ao livre exercício da sexualidade como parte dos direitos humanos. Pela primeira vez em um documento da ONU, as mulheres foram consideradas seres sexuais além de seres reprodutivos, detentoras de direitos humanos para decidirem livremente sobre sua sexualidade (CHACHAM; MAIA, 2004).

No entanto, ressalta-se que cada país possui princípios estruturadores do modelo sexual dominante que acabam fazendo com que as decisões de como as mulheres irão viver sua sexualidade não sejam tão livres assim.

No caso do Brasil, Faria (1998, p. 11-12) aponta que esses princípios são "a religião católica, a cultura europeia, o desenvolvimento do capitalismo e todas as mudanças ocorridas a partir dele". Para ela, a sexualidade, tal como a vivemos hoje, é marcada pela intenção de múltiplas tradições e práticas sociais, religiosas, morais, familiares, médicas e jurídicas, imbricadas às formas de resistência dos setores oprimidos e às próprias práticas sexuais e eróticas.

A autora argumenta que a sexualidade geralmente está associada a tabus, mistérios e desinformação e que, de acordo com a época:

[...] esses mecanismos de controle se modificam, porque o que é eficaz em determinado momento ou lugar não o é em outro. No momento atual, o excesso de informações sobre sexo é considerado mais um dispositivo de controle, no sentido de que produz um determinado discurso sobre a sexualidade que define as práticas de acordo com os objetivos de consumo. Ao questionar esse discurso, é importante reafirmar que a sexualidade é complexa e que, nesse campo, cada questão tem múltiplos significados e diferentes ligações (FARIA, 1998, p. 14).

A mesma autora ressalta, ainda, que sexo tem que ver com desejo e prazer, elementos que não se subordinam ao que a sociedade define como masculino ou feminino, "embora faça parte da cultura machista buscar fundir esses dois processos em um só e fazer com que mulheres e homens vivam sua sexualidade de acordo com seu gênero" (FARIA, 1998, p. 36).

O prazer, geralmente, é tido como um critério indicativo de positividade em relação à sexualidade, mas "o sexo pode ser fonte de ansiedade quando se tem prazer, assim como pode ser fonte de prazer em situações de desprazer, como na experiência da dor (física ou moral)" (CORRÊA, 1998, p. 77).

Russel (1955) cita Lins (2008, p. 182) quando afirma que "o casamento é para as mulheres a forma mais comum de se manterem, e a quantidade de relações sexuais indesejadas que as mulheres têm de suportar é, provavelmente, maior no casamento do que na prostituição".

Vance (1989) apud Faria (1998, p. 18) afirma que "a sexualidade é um terreno que coloca as mulheres numa tensão entre perigo e prazer, uma experiência que contém ao mesmo tempo alegria e prazer, tristeza e humilhação". Segundo ela, se não é uma experiência marcada somente pela subordinação ao poder masculino, também não é uma experiência de completa satisfação.

É grande o número de mulheres, de modo especial as vítimas de violência doméstica e familiar, que se veem forçadas a permanecer 
casadas e com esforço cumprirem suas obrigações sexuais com o marido em troca de casa, comida e algum conforto para elas e os filhos.

Segundo Lins (2008, p. 182), a maioria das mulheres, depois de algum tempo de casamento, faz sexo sem nenhuma vontade. Para a autora, esse sexo indesejado, por obrigação, é vivido também por mulheres economicamente independentes, que não necessitam do marido para mantê-las. A dependência emocional "acaba sendo tão limitadora, quanto à financeira. Ambas podem conduzir a uma vida sexual pobre e medíocre". Enfatiza ainda que, para algumas mulheres, imaginar-se sozinha, desprotegida, sem um homem ao lado, é percebido como insuportável.

Diante do exposto, percebeu-se que a ampliação dada ao conceito de sexualidade fez com que o sexo deixasse de ser encarado apenas como uma função natural de reprodução da espécie, para ser visto como um fenômeno mais global, que envolve a existência como um todo.

\section{Narrativas de Mulheres em Relações Conjugais Violentas}

As narrativas de vida apresentadas neste estudo são de cinco mulheres vítimas de violência doméstica e familiar atendidas no Juizado de Violência Doméstica e Familiar contra a Mulher, da Comarca de Teresina, PI, que conviveram e/ou estavam convivendo com seu cônjuge/companheiro agressor.

Buscou-se examinar, a partir das singularidades das mulheres, as recorrências nas suas falas e também as suas particularidades no que tange à questão da vivência da sexualidade e da violência doméstica e familiar que marcaram/marcam os seus relacionamentos amorosos.

\section{A vivência da sexualidade com o(s) parceiro(s)}

Durante as narrativas, as participantes contaram como se dava a vivência da sexualidade com os parceiros com quem conviveram e/ou ainda estavam convivendo. Eis o relato da entrevistada 01:

A gente era super bem. A gente conversava sobre tudo, não tinha aquela vergonha, alugava filme, assistia junto, a gente não tinha, assim, vergonha de nada. A gente, nesse lado, acho que ele não tem nada o que reclamar de mim nem eu dele. Sempre quando tinha alguma coisa errada, a gente conversava abertamente sobre aquele assunto. Mas foi a partir daí, da gravidez, porque quando eu tava grávida no começo do meu casamento, que eu perdi, não foi nem um tanto assim parecido porque minha barriga não começou a crescer e eu não comecei a sentir essas coisas que gestante sente, né? (ENT-01).

A entrevistada 01 enfatizou, no relato, que antes e durante a primeira gravidez, o casal se dava 'super bem' no que diz respeito à vivência da sexualidade, não tendo nem ele nem ela do que reclamar. No entanto, na segunda gravidez, quando o casamento estava em crise, a entrevistada ressaltou a dificuldade na interação sexual com o marido: "Mas era mais da minha parte do que dele. Eu que fazia tudo pra tentar reacender ele e poder salvar meu casamento porque já estava muito ruim a situação (choro)".

Segundo a entrevistada, o seu marido a acusava de traição e afirmava que o filho não era dele. Ela estava com ameaça de parto prematuro por conta de uma infecção causada por uma doença sexualmente transmissível (DST) transmitida por ele. O marido 
afirmava o contrário: "Dizia que eu, eu que peguei essa doença de outras pessoas, do homem, que eu passei, 'tô doente', que eu passei pra ele e tudo o mais". Todavia, informou que depois do nascimento do bebê, as relações sexuais eram determinadas pelo sono do filho: "A gente só passou um mês (risos), que foi só o resguardo só. E a gente aproveita quando o neném dorme! (risos)".

Segundo Ávila e Gouveia (1996), as mulheres buscam a sexualidade, e não somente tornar-se um corpo reprodutor, procurando a visibilidade multidimensional, que se traduz no prazer, produção e criação. Por conseguinte, a vivência diária mostra que a sexualidade da mulher possibilita mais que ser apenas reprodutora. Constatou-se essa busca da vivência da sexualidade de uma forma mais ampla pela entrevistada 01 .

Heilborn (1999) afirma que o tema da infidelidade masculina é revelador do panorama das relações de gênero. Para ela, as mulheres concebem tal questão como da ordem do regular, acreditando fazer parte da 'natureza masculina' a tentação de ter experiências sexuais variadas. Contudo, tal apreensão não redunda em atitudes de prevenção nas relações sexuais com os companheiros.

Loyola (1994, p. 16) ressalta que as mulheres encontram-se em posição desvantajosa para negociar o uso da camisinha em função do cenário das relações de gênero. Para ela, "sendo estas estruturadas com base em uma assimetria de prestígio e autoridade particularmente reveladora no encontro sexual, o exercício da decisão feminina torna-se problemático". Percebeu-se isso nos relatos da entrevistada 01 que, mesmo sabendo que o marido a estava traindo, não se preveniu, contraindo uma doença sexualmente transmissível (DST).

A entrevistada 02 narrou como vivenciava e como vivencia atualmente a sua sexualidade:
Todos os dias eu apanhava. Ele passava dia e noite fora e quando chegava de madrugada, ele me batia pra querer fazer relação comigo $e$ eu não aceitava. Por eu não aceitar, ele me batia, me batia mesmo, me espancava que deixava toda marcada. Aí, foi, deixa eu ver quantos anos... Foi uns seis? Foi uns seis anos nisso. [...] Eu sei lá, eu fico me sentindo assim um lixo, quando eu vou fazer amor com alguém. Eu penso que eи não sirvo pra aquela pessoa, que eu sirvo só pra matar a vontade daquela pessoa e tudo o mais. Eu me sinto assim um lixo, um ser desprezível. Foi até difícil me relacionar com esse que estou agora, eu nem queria. Eu disse que queria dar um tempo sozinha. Muita gente dava conselho, isso e tudo o mais, aí eu caí pensando que ia me dar bem, me dei bem no começo agora tá começando, como é que se diz, a mostrar como é que é. Aí tem hora que dá vontade de desistir, eu já pensei em fazer besteira comigo, mas toda vez quando eu penso, quando eu pego uma coisa pra fazer besteira comigo, a primeira coisa que vem na minha mente é meu filho, meu primeiro filho lá. Eu disse: "Eu não tô nesse mundo não é a toa não. Eu tenho que seguir meu caminho, pra mim saber até onde eu vou". Aí é desse jeito. [...] Hoje nós estamos, sabe nessa parte aí, eu pelo menos estou assim: quando eu vou fazer relação com ele, eu não me sinto bem assim como eu me sentia antes, entendeu? É como se eu tivesse fazendo com uma pessoa estranha, com um desconhecido. Acho que foi devido 
essas coisas todas que aconteceram comigo, essas confusões todas, essas brigas dentro de casa, as bebedeiras, tudo isso, foi tipo assim afastando o... Ele não me procurava mais, essas coisas e tudo mais. Aí, tipo assim, eu era uma pessoa muito apimentada, hoje em dia eu me sinto uma pessoa bem conformada, já não digo fria, digo conformada (risos) (ENT-02).

A fala da entrevistada 02 demonstrou o quanto se sente desvalorizada quando está tendo uma relação sexual e como foi difícil relacionar-se com o atual parceiro, tendo em vista a experiência traumática com o primeiro companheiro, com quem teve anos de sexo forçado. Atribuiu a isso alguns pensamentos suicidas que só não foram concretizados por pensar no filho mais velho. Já no que diz respeito ao relacionamento sexual com o seu atual parceiro, a entrevistada afirmou que este relacionamento mudou muito depois do nascimento do filho e dos conflitos existentes entre o casal, pois passou de 'mulher apimentada' a 'mulher conformada'.

Acredita-se que é isso que acontece com várias mulheres: inseridas em um contexto de violência doméstica e familiar, de desvalorização pessoal e social e de preocupação com a maternidade, perdem o desejo/tesão pelos companheiros agressores e, aos poucos, conformaram-se com a vivência de uma sexualidade medíocre dentro do relacionamento.

A entrevistada 03 falou sobre seu relacionamento sexual com o marido e outros parceiros que teve:

Ele, até que nossa relação era boa sobre esse aspecto. Ele mais, carinho mesmo assim, aquela atenção de marido e mulher eu não tinha, né. [...] Até que nesse lado, ele respeita. Eu passo de... Assim, quando eu não quero, ele não força. $E$, se eu saio do quarto, ele jamais chegou no outro quarto querendo me forçar a nada. Nesse lado aí... Agora em palavras, ele me maltrata muito. Ele, Ave Maria! [...] Mas eu, assim, o sexo, assim, eu não conseguia, eu tinha pra satisfazer ele, por eu ser mulher dele, né, a gente não pode, né, ficar negando, mas amor mesmo eu não sentia mais. [...] Aí começou também, eu conheci outras pessoas fora. É, tive um relacionamento com uma pessoa. Ele queria me assumir, queria que eu fosse morar com ele. Eu contei minha história toda. Era um rapaz muito bom, também separado. Aí ele pediu que eu fosse morar com ele, só que eu não tive coragem, pelos meus filhos. Não por ele, porque eu não sentia e nem sinto mais nada, não existe mais nada entre eu e ele. Aí eu resolvi acabar com esse rapaz que eu não conseguia me decidir, né, então eu optei por ficar perto dos meus filhos, apesar da minha infelicidade porque eu não tava feliz ali perto, mas tinha que ficar, né, perto dos meus filhos. [...] Mas, assim, eu com esses fora era muito melhor do que com ele dentro de casa. Eu tenho certeza que se eu tivesse optado por qualquer um desses, eu hoje estaria feliz. Apesar de não gostar e tudo, mas eu tenho certeza que eu estaria muito mais feliz do que com ele agora, porque eu com ele eu não sou feliz, eu não sou. Aliás, eu acho que eu nunca fui, nunca. Eu me acomodei com ele. Eu aprendi, assim, a viver... aguentar essas coisas (ENT-03). 
A referida entrevistada trouxe, em seus relatos, algumas contradições no aspecto da vivência de sua sexualidade com o marido, pois, ao mesmo tempo em que afirmou ser a relação deles boa nesse aspecto, que não havia sexo forçado, disse também que não o amava mais e fazia sexo para satisfazê-lo. Relatou, ainda, experiências extraconjugais que teve por não gostar do marido e objetivando somente ter relações sexuais, já que não sentia amor por nenhum desses outros parceiros e não tinha intenção de conviver maritalmente com eles, por não ter coragem de abandonar os filhos.

Percebe-se que, ao longo de muitos séculos, sempre:

[...] se tentou impor às mulheres que a vontade dos homens é que vale. Ainda hoje elas são estimuladas a agradar aos homens e, em geral, aparece pouco a satisfação de seu próprio desejo. Aparece menos ainda a importância de sua autonomia e escolha. Em função disso, existe toda uma parafernália do que precisam fazer para estarem sempre sedutoras, mas o mais grave é o fato de sua vontade e seu desejo não contarem. Por isso, é comum que realizem práticas sexuais que não desejam, a fim de não serem consideradas inadequadas. Muitas vezes, elas têm relações sexuais sem querer, porque o seu "não" é desconsiderado (FARIA, 1998, p. 15-16).

Heilborn (1999, p. 10) ressalta que "os relatos femininos manifestam cálculos na escolha de parceiros e na comparação entre eles, bem como decisões sobre o momento de iniciar a vida sexual e de romper relacionamentos". Para ela, ocorre por vezes uma visão psicologizante de certos problemas nessa área, como pessoais e não mais completamente referidos às regras sociais.

Historicamente, as mulheres vêm fazendo escolhas, principalmente visando ao bemestar dos seus filhos, mesmo que em detrimento de sua própria felicidade e realização pessoal e amorosa. Uma dessas escolhas acaba sendo não romper $o$ relacionamento com o parceiro e continuar tendo o seu 'não' desconsiderado por conta das convenções sociais que as considerariam inadequadas caso as questionassem.

A entrevistada 04 relatou a trajetória da vivência da sua sexualidade desde o momento da primeira relação sexual até o relacionamento com o primeiro parceiro com quem viveu em união estável e o que mais a violentou:

Eu... porque na época eu fiquei assim, tipo assim, deprimida. Eu não tava assim querendo falar com ninguém, devido o que aconteceu comigo, tá entendendo? Quando eu tive um encaminhamento assim com a psicóloga, ela começou a abrir mais minha mente e tudo. Chegou ao ponto até deu tomar remédio! Eu tomava Diazepan e Amitril, na época. Porque eu queria, aconteceu isso comigo, deu não era mais nada, e eu pensava que era coisa do outro mundo e nisso eu comecei a ficar deprimida, sem querer sair mais pra lugar nenhum, aí o pai foi observando o meu modo, o jeito que eu tava, eu não tava mais nem querendo viver, namorar com o meu namorado, eu não tava mais querendo, eu não tava mais indo na casa da família dele. Eu já tava, assim, isolada das pessoas que eu vivia. Eu não tava querendo mais ir pro colégio, aí nisso o pai me 
internou pra mim fazer um tratamento. Aí devido as conversas que eu tive no [nome de antigo hospital psiquiátrico de Teresina], aí fui tomar remédio, aí depois é que eu fui voltar ao meu normal. Não quis mais saber dele, eu não quis mais saber do meu namorado, de jeito nenhum. Ele andava atrás de mim, eu dizia que não queria mais. $\mathrm{Eu}$ fiquei assim, tipo assim, desorientada, não tem? Eu pensava que ele tinha feito uma coisa assim muito grave comigo na época. Eu não quis mais saber dele, eu não quis mais de jeito nenhum. [...] Aí eu conheci outro paquera, aí nesse paquera só curtia assim mesmo, saia pra me divertir, bebia, não tem essas coisas? Mas assim não deu ficar assim com ele ainda não, entendeu? Depois, ele foi indo, foi conversando, aí é que eu comecei a conhecer, entendeu, realmente o sexo, como era. Aí esse segundo que me ensinou como era, me tratou bem, mas era só paquera, não queria nada sério comigo. Assim, eu não tinha vontade de ficar nada sério com ele, na época, só curtindo mesmo. Que, às vezes, nós saíamos, ele só ligava, ia me buscar em casa, saíamos. Ele que, esse segundo que fez eu conhecer o que era sexo, mas também não peguei filho dele. [...] $\hat{E}$, eu tive meu primeiro parceiro foi assim uma vida sofrida. Eu achei muito sofrida porque eu vivia com ele através de ameaça, né. Ele me batia, quando chegava em casa, se chegava bêbado. Ele era usuário na época, e aí eu sempre tinha fé em Deus, né. Ele dizia assim: "Eu não te deixo; eu só te deixo se um dia eu chegar a morrer". Aí me batia, tinha mulheres na rua, quando chegava me judiava,queria que eu transasse com ele a força, aí às vezes transava comigo, cuspia na minha cara. "Isso aí, fulera!". "Pah" na minha cara. [...] Puxava os meus cabelos, queria às vezes eu até menstruada ele queria transar comigo e eu dizia: "Eu não quero, eu tô menstruada". "Pois bora, dá um jeito bem aí e vira tuas partes. Aí num tem esse buraco? Aí não tem 'bode' não, não tem 'bode' não, não sei o que”. E aí ele ia no meu ânus, me "comia" a força mesmo, me puxava, eu chorava e quando terminava ele cuspia na minha cara (choro). Eu nunca me esqueci disso (ENT-04).

A trajetória sexual da entrevistada 04 é marcada por sabores e dissabores, sendo estes últimos mais frequentes em sua vida. Da experiência da primeira relação sexual, relatou que ficou um trauma por acreditar que o namorado tinha feito algo de muito grave com ela e, na época, pela desvalorização social por não ser mais virgem. Tais fatos a deixaram deprimida a ponto de o pai interná-la em um hospital psiquiátrico para fazer um tratamento, pois ela não tinha mais vontade de viver nem de realizar suas atividades cotidianas, como ir à escola, estar com familiares e amigos e namorar.

Depois de superado o trauma, a entrevistada 04 informou ter tido algumas 'curtições' com paqueras. A 'curtição' mais longa durou três anos e relatou que foi ele que a fez conhecer realmente o que era sexo. Segundo a entrevistada, esse relacionamento acabou quando ela descobriu, através da própria esposa do paquera, que ele era casado.

Já a sexualidade com o primeiro 
companheiro, com quem viveu em união estável por oito anos, foi marcada por violência física, psicológica, moral e sexual. $\mathrm{O}$ mesmo a agredia fisicamente e a forçava a fazer sexo vaginal e anal, xingava-lhe, ameaçava-lhe e cuspia em seu rosto depois das relações sexuais.

Faria (1998, p. 12) retrata que, "para as mulheres, o sexo fora do casamento já foi severamente punido com morte, proibição legal, perda de direito sobre os filhos, injúria, desvalorização social", dentre outros. Percebeu-se esse sentimento de desvalorização social nas falas das entrevistadas quando afirmavam que por não serem mais virgens, "não eram mais nada", "não valiam mais nada".

Segundo Heilborn (1999, p. 10), “o cenário do intenso controle familiar, de categorização moral do sexo e de papéis tradicionais de gênero em relação aos parceiros não desapareceu por completo". Percebeu-se isso nos relatos das entrevistadas 02 e 04, que tinham o seu "não" desconsiderado, e com a entrevistada 03, que fazia sexo para satisfazer o marido porque acreditava que não podia lhe negar tal ação.

Faria (1998, p. 12) afirma que a sexualidade é política, pois "há uma hierarquia estabelecida entre as práticas e a pessoa será recompensada ou castigada, de acordo com o lugar que suas práticas ocupem nessa hierarquia".

Observou-se, nas narrativas das pesquisadas, essa forte influência dos papéis tradicionais de gênero nas relações violentas em que estiveram/estavam inseridas. Isso não foi diferente em relação à sexualidade, âmbito em que foram "castigadas" por uma hierarquia que relegou e ainda relega o seu "sim" ao segundo plano.

No entanto, para Foucault (2012, p. 14), as mulheres inseridas desigualmente nas suas relações conjugais, de alguma maneira, resistem ao "poder do macho", pois "[...] onde há poder há resistência, não existe propriamente o lugar de resistência, mas pontos móveis e transitórios que também se distribuem por toda a estrutura social". O autor utiliza a noção de "relações de poder" como um instrumento de análise para explicar a produção de saberes em determinado contexto social. O cerne das suas análises está nos "micropoderes" que se manifestam em níveis variados e pontos diferentes da rede social. Segundo ele, esse caráter relacional do poder:

[...] implica que as próprias lutas contra o seu exercício não possam ser feitas de fora, de outro lugar, do exterior, pois nada está isento de poder. Qualquer luta é sempre resistência dentro da própria rede do poder, teia que se alastra por toda a sociedade e a que ninguém pode escapar: ele sempre está presente e se exerce como uma multiplicidade de relações de força (FOUCAULT, 2012, p. 14).

Sendo assim, acredita-se que o referido autor vê a sexualidade dentro das relações de poder e exercendo micropoderes, principalmente como uma forma de controle da vida das pessoas. Dentro dessas relações, a sexualidade seria uma forma de articulação às mais variadas estratégias de poder, poder este que fala da sexualidade e para a sexualidade.

A sexualidade se manifesta de forma diferente em cada etapa do desenvolvimento do ser humano. Ela é construída ao longo da vida e "encontra-se necessariamente marcada pela história, cultura e ciência, afetos e sentimentos dos indivíduos, assim como pelas suas experiências de vida" (FERNANDES; NASCIMENTO, 2011, p. 301).

A entrevistada 05 falou sobre a vivência 
da sexualidade com seus quatro parceiros:

Ah, nesse momento aí era o maior
amor do mundo! Todos os quatro,
né, era o maior amor do mundo. Nenhum tentou fazer nada a força. Esse agora, esse atual, quando eu não quero, não quero e pronto. Ele também não mexe nem nada. Nesse sentido, os meus relacionamentos todos foram satisfatórios. [...] Aí eu tô me encontrando com o meu exmarido (risos), né, a gente se encontra de vez em quando, a gente sai, mas sempre com o pé atrás. Eu tenho medo de dar uma chance $e$ voltar a ser tudo como era antes. Eu prefiro assim do jeito que tá, só que ele quer que eu more com ele, mas eu queria assim, a gente ficar se encontrando, pelo menos evita de ter briga, evita de ter discussão, ciúme, essas coisas, se tornaria melhor. É assim. [...] Nós estamos há dois meses nos encontrando (risos). E nesses dois meses está tudo bem, tudo ótimo. Ele é o tipo de pessoa assim que quando eu quero ir pra qualquer lugar, se ele não tiver trabalhando, ele me leva, ele me traz, ele é assim. A outra pessoa que eu vivo não tá sabendo. Deus me livre! (risos). Ele não tá sabendo. Nem meus filhos (ENT-05).

Em suas narrativas, a entrevistada 05 afirmou ter tido uma vivência satisfatória de sua sexualidade com os quatro parceiros e que os mesmos nunca a forçaram a manter relações sexuais. Relatou estar se encontrando escondido dos filhos e do seu atual companheiro com o parceiro com quem viveu em união estável antes deste atual. Porém, teme voltar a viver novamente com ele, pois foi justamente o que mais a agrediu e a traiu com outras mulheres.

Destaca-se que, em seus relatos, não foram encontrados indícios concretos para que se possa afirmar o que essa entrevistada considerava 'satisfatório' na vivência de sua sexualidade com os parceiros. Depois de desligado o gravador de voz digital, a mesma afirmou que o terceiro companheiro, este com quem está se encontrando, é o que mais mexe com ela emocional e sexualmente. Disse que só o deixou, na época, porque cansou das traições dele e não por conta das violências sofridas.

Faria (1998) argumenta que o Brasil não é diferente de outros países e que nele não se tem uma, mas muitas sexualidades brasileiras. Para ela, no que se refere à sexualidade feminina, em um contexto de debate de várias questões colocadas pelo feminismo na defesa da autonomia e emancipação sexual das mulheres, convivese cotidianamente com a diversidade de experiências. Percebeu-se, com maior ênfase, essa diversidade de experiências nos relatos das entrevistadas 03, 04 e 05.

De um modo geral, observou-se, nas narrativas das entrevistas, que a violência doméstica e familiar e a maternidade apareceram como fatores que repercutiram na vivência da sexualidade. Algumas vezes, as relações sexuais foram relatadas como momentos satisfatórios e também de estratégias para manter o relacionamento. As traições dos companheiros com outras mulheres apareceram em vários relatos $\mathrm{e}$ duas das pesquisadas referiram terem tido e/ou ainda estarem tendo relações extraconjugais. A sexualidade, como algo mais que coito, como intimidade, expressa na forma de sentir e de como as pessoas tocam e são tocadas, apareceu apenas nos relatos da entrevistada 01.

Acredita-se que a sexualidade tenha sido uma estratégia de poder dos parceiros para mostrarem o domínio que tinham sobre 
o corpo e a vida dessas mulheres. E apesar de não se ter embasamento, nos relatos das participantes, para se chegar a alguma conclusão, indaga-se: quem sabe se a sexualidade também não foi usada por elas como estratégia de poder para manterem o relacionamento, mesmo dentro de um contexto de violência doméstica e familiar, mas também de afeto por esses parceiros com quem decidiram compartilhar a sua vida?

Desse modo, faz-se necessária uma reflexão mais profunda sobre a sexualidade das mulheres, principalmente das que foram/são vítimas de violência doméstica e familiar, seu significado, a maneira como ela se processa e, mais ainda, faz-se necessário um questionamento sobre os padrões morais e as relações de poder na sociedade.

\section{Considerações Finais}

A sexualidade, como objeto de estudo, tem sido investigada e discutida nas mais diversas disciplinas. A experiência sexual humana, assim como qualquer outra experiência humana, é produto de um complexo conjunto de processos sociais, culturais, históricos e, também, biológicos. O corpo e seus usos estruturam-se como linguagem que simboliza, significa e comunica as expectativas abarcadas por um determinado contexto histórico e cultural.

Dada a grande importância que especialistas de várias áreas dão ao tema e, mais ainda, a popularidade da temática em todos os meios de comunicação de massa, é preocupante como as informações sobre como as mulheres exercem sua sexualidade são escassas no Brasil. As pesquisas enfocam mais o comportamento reprodutivo e/ou a saúde sexual das mulheres. Tal fato se exacerba no que diz respeito à sexualidade das mulheres vítimas de violência doméstica e familiar. É como se essas mulheres fossem seres assexuados. No entanto, não foi isso o que se percebeu nas narrativas das mulheres entrevistadas.

A pesquisa abordou a sexualidade das mulheres vítimas de violência doméstica e familiar, atendidas no Juizado de Violência Doméstica e Familiar contra a Mulher, da Comarca de Teresina, PI. Entende-se que, mesmo considerando todas as diferenças de uma mulher para outra, as mulheres brasileiras têm em comum a vivência de sua sexualidade em uma sociedade machista e patriarcal.

Quando se tratou da categoria 'a vivência da sexualidade com o(s) parceiro(s)', constatou-se a dificuldade dessas mulheres em falarem sobre a sua sexualidade, pela timidez, tabus que permeiam a temática e principalmente pelas lembranças, na maioria das vezes negativas, destes momentos vividos. Por mais que os posicionamentos conceituais e teóricos apresentados e defendidos neste estudo tragam a sexualidade como algo bem mais amplo que apenas o sexo/coito, ao abordarem o assunto, as entrevistadas referiram-se praticamente ao ato sexual em si, ressaltando o estupro conjugal, o sexo sem vontade apenas para satisfazer o companheiro $\mathrm{e}$ as relações sexuais extraconjugais.

Foi bastante marcante, nos relatos, o quanto essas mulheres ficaram com a autoestima baixa, sentiram-se 'um nada', desvalorizadas íntima e socialmente depois que perderam a virgindade. Enfatiza-se como elas, durante os seus relacionamentos, anularam-se e/ou ainda se anulam no seu direito de viverem sua sexualidade com prazer e alegria em detrimento de simplesmente satisfazerem os companheiros, de cumprirem com uma obrigação marital.

Todavia, foi interessante perceber que algumas já demonstravam iniciativa de 'procurar' o parceiro quando queriam ter relações sexuais e desfrutavam do 'sexo sem compromisso' em relações extraconjugais, 
pelo simples fato de desejarem ter relações sexuais mais prazerosas do que as que estavam tendo com os seus cônjuges/companheiros.

$\mathrm{O}$ fato de os parceiros considerarem-nas como objeto e desrespeitarem o seu 'não', marcou negativamente a vivência da sexualidade dessas mulheres. No entanto, a vivência prazerosa e sem violência dessa sexualidade com alguns parceiros foi ressaltada como algo satisfatório dentro do relacionamento.

Por fim, ao analisar os marcos teóricos adotados nesta pesquisa e as narrativas de vida das mulheres vítimas de violência doméstica e familiar, acredita-se que a discussão da temática não se esgota nesta pesquisa, mas pretende-se colaborar com o debate que se faz necessário para superar as visões simplistas que escamoteiam o fenômeno ao concebê-lo, apenas, nas particularidades dos sujeitos.

\section{Referências}

ÁVILA, Maria; GOUVEIA, Tassiane. Notas sobre direitos reprodutivos e direitos sexuais. In: PARKER, Richard; BARBOSA, Regina Maria. Sexualidades brasileiras. Rio de Janeiro: Relume Dumará, 1996, p.160 - 172.

BERTAUX, Daniel. Narrativas de vida: a pesquisa e seus métodos. Natal: EDUFRN; São Paulo: Paulus, 2010.

BRASIL. Ministério da Saúde. Diretrizes e normas regulamentadoras de pesquisa envolvendo seres humanos (Resolução $n^{\circ}$ 466/12 do Conselho Nacional de Saúde). Rio de Janeiro: Fiocruz, 2012.

CHACHAM, Alessandra Sampaio; MAIA, Mônica Bara. Corpo e sexualidade da mulher brasileira. In: VENTURINI, Gustavo; RECAMÁN, Marisol; OLIVEIRA, Suely.
(Org). A mulher brasileira nos espaços público e privado. 1 ed. São Paulo: Editora Fundação Perseu Abramo, 2004, p. 75 - 86.

CHAUÍ, Marilena. Repressão sexual: essa nossa desconhecida. São Paulo: Brasiliense, 1984.

CORRÊA, Marilena Villela. Sexo, sexualidade e diferença sexual no discurso médico: algumas reflexões. In: LOYOLA, Maria Andréa. A sexualidade nas Ciências Humanas. Rio de Janeiro: EdUERJ, 1998, p. $69-91$.

FARIA, Nalu. Sexualidade e Gênero: uma abordagem feminista. São Paulo: SOF, 1998.

FERNANDES, M. A.; NASCIMENTO, F. Z. F. O. Sexualidade do adolescente: uma abordagem interdisciplinar. In: NERY, Inês Sampaio et al. (Org). Gravidez na adolescência: prevenção e riscos. Teresina: EDUFPI, 2011, p. 293 - 302.

FOUCAULT, Michel. História da sexualidade I: a vontade de saber. Rio de Janeiro: Edições Graal, 1988.

FOUCAULT, Michel. Microfísica do poder. Tradução de Roberto Machado. 22a Ed. Rio de Janeiro: Edições Graal, 2012.

GARCIA-ROZA, Luis Alfredo. Freud e o inconsciente. 18 ed. Rio de Janeiro: Jorge Zahar Ed., 2001.

GROSSI, Miriam Pillar. Identidade de gênero e sexualidade. Revista Antropologia em Primeira Mão, p. 1 - 18, 1998.

HEILBORN, Maria Luiza. Construção de si, gênero e sexualidade. In: HEILBORN, Maria Luiza (Org.). Sexualidade: o olhar das 
ciências sociais, IMS/UERJ. Rio de Janeiro: Editora Zahar, 1999, p. 01-18.

LIMA, Marwyla. A importância da análise das relações patriarcais de gênero para a compreensão da Lei Maria da Penha. In: LIMA, Rita de Lourdes de; GURGEL, T.; QUEIROZ, Fernanda Marques. (Org). Gênero e Serviço Social: múltiplos enfoques. Natal, RN: EDUFRN, 2012, p. 8196.

LINS, Regina Navarro. A cama na varanda: arejando nossas ideias a respeito de amor e sexo: novas tendências. Ed. rev. e ampliada. 3. ed. Rio de Janeiro: BestSeller, 2008.

LOYOLA, Maria Andréa. Aids e sexualidade: o ponto de vista das ciências sociais. Rio de Janeiro, Relume-Dumará: UERJ, 1994.

ORGANIZAÇÃO MUNDIAL DE SAÚDE. Instruccion en cuestiones de sexualidad humana: formacion de profesionales de la salud. Genebra: OMS, 1975.

SANTOS, Inês Maria Meneses; SANTOS, Rosângela da Silva. A etapa de análise no método história de vida: uma experiência de pesquisadores de enfermagem. Revista Texto \& Contexto - Enfermagem, v. 17, n. 4, p. 714 - 719, 2008.

TAQUETTE, Stella. Sexualidade na adolescência. In: Ministério da Saúde, Secretaria de Atenção à Saúde, Departamento de Ações Programáticas Estratégicas. Saúde do adolescente: competências e habilidades. Brasília-DF: Ed. Ministério da Saúde, 2008, p. 205 - 212. 